\title{
Local Mesenchymal Stem Cell Therapy in Experimentally Induced Colitis in the Rat
}

\author{
Fernando de la Portilla ${ }^{1}$, Yaiza Yuste ${ }^{2}$, Sheila Pereira ${ }^{2}$, \\ Carolina Olano $^{3}$, Maria Victoria Maestre ${ }^{1}$, Francisco Javier Padillo \\ ${ }^{1}$ Department of General and Digestive Surgery, Unit Colorectal Surgery, "Virgen del Rocio" \\ University Hospital/IBiS/CSIC/University of Seville, Seville, Spain \\ ${ }^{2}$ Institute of Biomedicine of Seville (IBiS), "Virgen del Rocío" University Hospital/IBiS/CSIC/University of Seville, Seville, Spain \\ ${ }^{3}$ National Institute of Toxicology and Forensic Sciences, Seville, Spain
}

\begin{abstract}
Background: Multipotent mesenchymal stem cells (MSCs) have been used in inflammatory bowel diseases because of their immunomodulatory and regenerative properties. We investigated their local use in an experimental model of colitis in the rat.

Materials and Methods: Colitis was induced into 20 Wistar rats with local TNBS instillation. Allogeneic stem cells were derived from rat adipose tissue and labeled with $\mathrm{PKH} 2$ linker dye with creation of a control and a second group treated by a local injection into the rectal wall of $2 \times 10^{6}$ allogeneic adipose tissue-derived stem cells (ADSCs). The thicknesses of different components of the rectum were measured with comparisons made in different parts of the colon of the Hunter inflammatory score. PKH2-dyed ADSCs were detected by fluorescence microscopy.

Results and Conclusions: Total colitis was induced in 19/20 rats with homing of fluorescent ADSCs. to the crypt base and perivascular space of the submucosa. There were no differences in component rectal wall thicknesses with a higher Hunter score in the treated group compared with the controls, in the rectum $(3.8 \pm 2.74$ vs. $1.5 \pm 2.37$, respectively; $\mathrm{p}=0.017)$ and in right colon $(2.5 \pm 1.08$ vs. $0.20 \pm 0.42$, respectively; $\mathrm{p}=0.0001)$. Local colonic injection of allogeneic adipose stem cells. in experimental colitis is feasible and safe. There is demonstrable homing of cells in chemically-induced colitis both to the treated region and parts of the colon distant to the MSC treatment site. Such cells readily proliferate in vitro and could potentially be a source for future treatment of resistant disease.
\end{abstract}

Keywords: Mesenchymal stem cells, Inflammatory bowel disease, Animal models, Colitis

Received: December 23, 2017, Revised: March 5, 2018,

Accepted: March 11, 2018, Published online: April 30, 2018

Correspondence to Fernando de la Portilla

Department of General and Digestive Surgery, Unit Colorectal

Surgery, "Virgen del Rocío" University Hospital/IBiS/CSIC/

University of Seville, Avda Manuel Siurot s/n 41013, Seville, Spain

Tel: +34954314292, Fax: +34955012292

E-mail: fportilla@us.es

(a) This is an open-access article distributed under the terms of the Creative Commons Attribution Non-Commercial License (http://creativecommons.org/ licenses/by-nc/4.0/), which permits unrestricted non-commercial use, distribution, and reproduction in any medium, provided the original work is properly cited.

Copyright (c) 2018 by the Korean Society for Stem Cell Research

\section{Introduction}

Inflammatory Bowel Disease (IBD) encompassing both Crohn's Disease (CD) and Ulcerative Colitis (UC) affects more than 3.5 million people across the United States alone, with a demonstrated steep increase in incidence over the last half century (1). The pathogenesis of IBD is still not well understood, but involves genetic, environmental and immunological contributions implicating a dynamic interaction between the gut microbiota, the mucosa and the host immune system (2). This issue is complex with genetically susceptible individuals exposed to environmental triggers which affect the gut microbiome and 
which result in specific interaction between the NOD-2 receptor protein and bacterial lipopolysaccharide (3). Although there are many xenomodels of IBD which have improved our understanding of disease pathogenesis and progression, each method, whether induced by chemical means or via immunologic manipulation or by gene targeting, has limitations in the representation of the observable characteristics of human disease $(4,5)$.

Mesenchymal stromal cells (MSCs) are currently being extensively examined in a range of regenerative and immune disorders and appear comparatively attractive as therapeutic agents in IBD, largely because of their immunomodulatory and regenerative properties as well as their ready in vitro proliferative capacity (6). The techniques for MSC isolation and expansion vary with harvesting from a range of sources including bone marrow, adipose tissue, umbilical cord and placenta (7). These multipotent cells have been defined by the International Society for Cellular Therapy (ISCT) with plastic adherence in standard in vitro culture, specific expression of surface CD markers (CD105, CD73 and CD90), non-expression of other cell-surface markers (CD45, CD34, CD14, CD11b, CD79, CD19 and HLA-DR) and a propensity towards osteoblast, adipocyte or chondroblast differentiation in vitro (8). This original ISCT description has been further supplemented by immunological definition where MSCs must show an in vitro response to IFN- $\gamma$ and TNF- $\alpha$ with a discrete reproducible functionality on cellular expansion, measurable immunoresponsiveness to infusion and clinical efficacy in some xenotransplantation models (9).

Following a case report in 1998 of the improvement of $\mathrm{CD}$ activity in a lymphoma patient undergoing autologous bone marrow transplantation (10), an open-label randomized, phase II study was initiated in 2006 in order to assess the safety and efficacy of the intravenous administration of allogeneic bone marrow-derived MSCs in patients with moderate or severe CD (11). Although this group reported a significant decrease in the Crohn's Diseases Activity Index (CDAI) in $9 / 10$ patients after 28 days of treatment, an independent 2009 Phase III trial enrolling 210 patients was halted after a higher than expected level of clinical responsiveness in the placebo arm (12). Recently, intrafistular injection of allogeneic adipose-derived MSCs (ADSCs) has shown clinical improvement in perianal CD with complete remission in $50 \%$ of the cases treated by 24 weeks when compared with placebo (13). The aim of our preliminary study was to evaluate the efficacy of the local injection of ADSCs in the colon of a rodent chemical colitis model.

\section{Materials and Methods}

The project (PEIBA 0156-N-16) was approved by our Animal Ethics and Welfare Committee and conducted in accordance with the published doctrines of the European Union directive 2010/63/EU concerning the protection of animals used for scientific purposes. Twenty female Wistar rats (185 210 gm weight) were obtained from the local animal centre (Institute of Biomedicine, Seville) with all animals housed in separate cages in a room with acclimatized temperature under a 12 hour day/night cycle and with free access to water and food. Colitis was induced in the rats using 2,4,6 - trinitrobenzenesulfonic acid (TNBS; P2297, Sigma-Aldrich) diluted 30\% with Ethanol at a standardized dose of $50 \mathrm{mg} / \mathrm{kg}$ in accordance with other reports $(14,15)$. This solution was administered rectally after negotiation of the anal canal with a $21 \mathrm{G}$ Abbocath cannula in a total volume of $1 \mathrm{~mL}$ as previously described (16). In order to diminish rectal reflux, the animals were maintained in a Trendelenburg posture following TNBS administration for a minimum of 15 minutes.

\section{Mesenchymal stromal cell characterization}

The ADSC treatment cells were derived from the Cell Bank of the Jiménez Díaz Foundation (Madrid, Spain) after extraction from the abdominal adipose tissue obtained from 2 female Wistar rats. The ADSCs were isolated according to ISCT and IFATS criteria (17) by collagenase digestion of the liposuction with subsequent density-gradient centrifugation $(11,18,19)$. Thawed cells were washed with a mixture of Low Glucose DMEM medium, 4.0 $\mathrm{mM} \mathrm{L}$-Glutamine and $110 \mathrm{mg} / \mathrm{L}$ Sodium Pyruvate $(\mathrm{SH}-$ 30021.01, HyClone) supplemented with $10 \%$ fetal bovine serum (F7524, Sigma-Aldrich) and 1\% Penicillin/Streptomycin (15140122, GIBCO). Washing resulted in cell purification with extraction of heterogeneous cell populations, eliminating hematopoietic cellular debris, endothelial cells and their progenitors and fibroblasts. Aspirates of the non-adherent ADSCs were then restored into fresh culture medium which provided a greater comparative yield than other stem cell sources (20). After separation from the stromal fraction, the ADSCs were expanded in in vitro culture by adhesion to plastic plates for 24 hours. Cells were seeded at a density of 50,000 cells $/ \mathrm{cm}^{2}$ and incubated at $37^{\circ} \mathrm{C}$ in $5 \% \mathrm{CO}_{2}$ for $12 \sim 14$ days, changing the culture medium every $3 \sim 4$ days. Upon reaching $80 \sim 90 \%$ confluence, the cells were washed with Trypsin-EDTA (25300062, GIBCO) and then frozen for later use. Once the cells were needed, they were thawed and subcultured in similar fashion. The cells were labeled with PKH26 (Mini26-1Kt, 
Sigma-Aldrich) immediately prior to use resulting in a yellow-orange coloration which incorporates into the lipid region of the cell membrane identified by fluorescence at $551 \mathrm{~nm}$ excitation and $567 \mathrm{~nm}$ emission (21).

\section{ADSC treatment of animals}

All animals were anesthetized for both the induction of colitis and for definitive ADSC treatment, with an intraperitoneal injection of Ketamine and Xylazine, at doses of $80 \mathrm{mg} / \mathrm{kg}$ and $10 \mathrm{mg} / \mathrm{kg}$ body weight, respectively. Following anesthesia procedures were performed via a midline laparotomy. The protocol permitted the separation of treatment groups whereby 3 days after colitis induction, the animals were equally divided into blinded treatment and control arms. The study group was treated by local injection into the wall of the upper rectum with $2 \times 10^{6}$ allogeneic ADSCs and the control group was treated in similar fashion but with saline. Animals were sacrificed 10 days after the treatment, using an intraperitoneal injection of Pentobarbital Sodium diluted to $100 \mathrm{mg} / \mathrm{kg}$ and with subsequent neck dislocation. At necropsy, samples of the rectum and the descending, transverse and ascending colon were collected with one half of the samples fixed in $4 \%$ formaldehyde for hematoxylin and eosin histology and the other half frozen in liquid nitrogen for fluorescence microscopy. The severity of colitis along with the nature of the cell migration into the colon and the measurable thickness of the intestinal wall were determined. Colitis severity was recorded using the clinical disease scoring system devised by Hunter et al. (22) based upon 5 criteria with a maximum score of 5 . These included: (1) $>10 \%$ loss of body weight (recorded as 0 or 1), (2) A wet anus with soft stool vs. an empty colon $(0 \sim 1)$, (3) anal bleeding (0 or 1), (4) Macroscopic ulcers (0 or 1) and (5) death (1). The thickness of the different components of the rectal wall was measured on microscopic slides using image processing software, (Image 1, Python Imaging Library) comparing the control and treated groups and taking 4 representative measurements with recording of the mean value.

\section{Statistic analysis}

Statistical analysis was performed using the $\operatorname{IBM}^{\circledR}$ SPSS $^{\circledR}$ Statistics 19 package (Chicago, IL). Quantitative variables were expressed as means and standard deviations. Comparisons between the two groups were made with the Mann-Whitney U test (with the Bonferroni correction) and the Student $t$-test where appropriate. Comparisons of continuous variables were made with the Pearson Chi square test and the Fisher's exact test where appropriate. A p value $<0.05$ was considered statistically significant.

\section{Results}

The macroscopic and microscopic lesions induced by TNBS were confirmed in all of the rats and were similar to that described by other workers (14). Also, a previous study was performed by us in which proved that the method followed was correct. There was no clinical consequence in any animal (change in weight, alterations in diet or water intake or decrease in stool frequency) (Fig. 1). Total colitis was induced in 19/20 rats with the predominance of inflammation macroscopically and microscopically noted in the rectum and right colon. The capacity for ADSCs to migrate and to engraft to the area of tissue damage as well as the semi-quantitative and

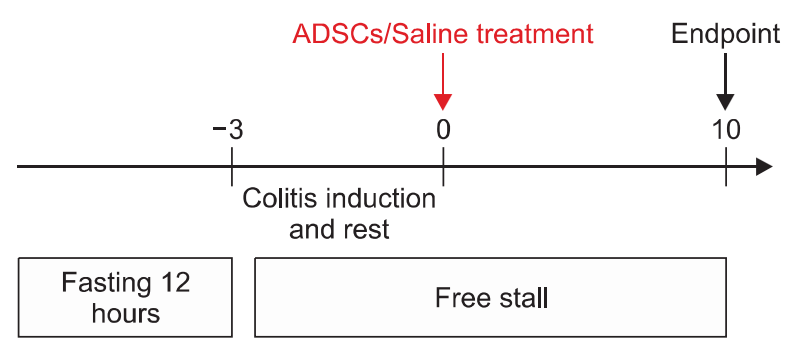

Body weight measurement

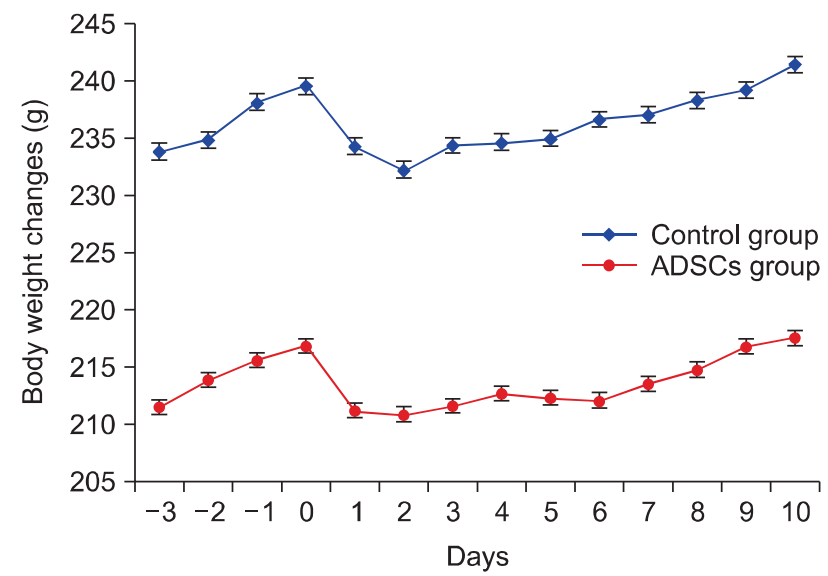

Fig. 1. Left image: Scheme of the treatment. The day of ADSCs injection and saline in the treated groups was defined as day 0 . Right image: Body weight changes over time in both groups. 
quantitative degree of inflammation was assessed in sections of the rectum and colon. Fluorescence microscopy showed a transmural colonic migration in all ADSC-treated animals at 10 days following treatment with a correlation between the degree of inflammation and the number of infiltrating ADSCs. This effect was particularly noted around the base of the crypts of Leiberkühn and in the perivascular space of the submucosa (Fig. 2). Table 1 shows the thickness measurements of the different intestinal components between the control and the treated groups with no differences noted in any component of the intestinal wall or overall. Fig. 3 shows the comparative Hunter scores between the treatment and control groups for the different sections of the colon. The Hunter score was significantly greater in the control group when compared with the treated group for the rectum $(3.8 \pm 2.74$ vs. $1.5 \pm 2.37$, respectively; $p=0.017$ ) and for the right colon
$(2.5 \pm 1.08$ vs. $0.20 \pm 0.42$, respectively; $p=0.0001)$. There were no differences between the groups either for the descending colon $(1.1 \pm 1.97$ vs. $0.3 \pm 0.48$, respectively; $\mathrm{p}=0.47)$ or for the transverse colon $(1.7 \pm 2.36$ vs. $0.7 \pm 2.21$, respectively; $\mathrm{p}=0.19)$. The appearances of the Haematoxylin and Eosin histology for the different parts of the colon between the control and treatment groups are also represented in Fig. 4.

\section{Discussion}

Our preliminary study has shown that in an established rat model of colitis, locally injected generic adipose-derived mesenchymal stem cells migrate into the base of the crypts of Leiberkühn with an objectively diminished clinical score of colonic inflammation in treated animals. Normal mucosal integrity is a balanced interaction between the
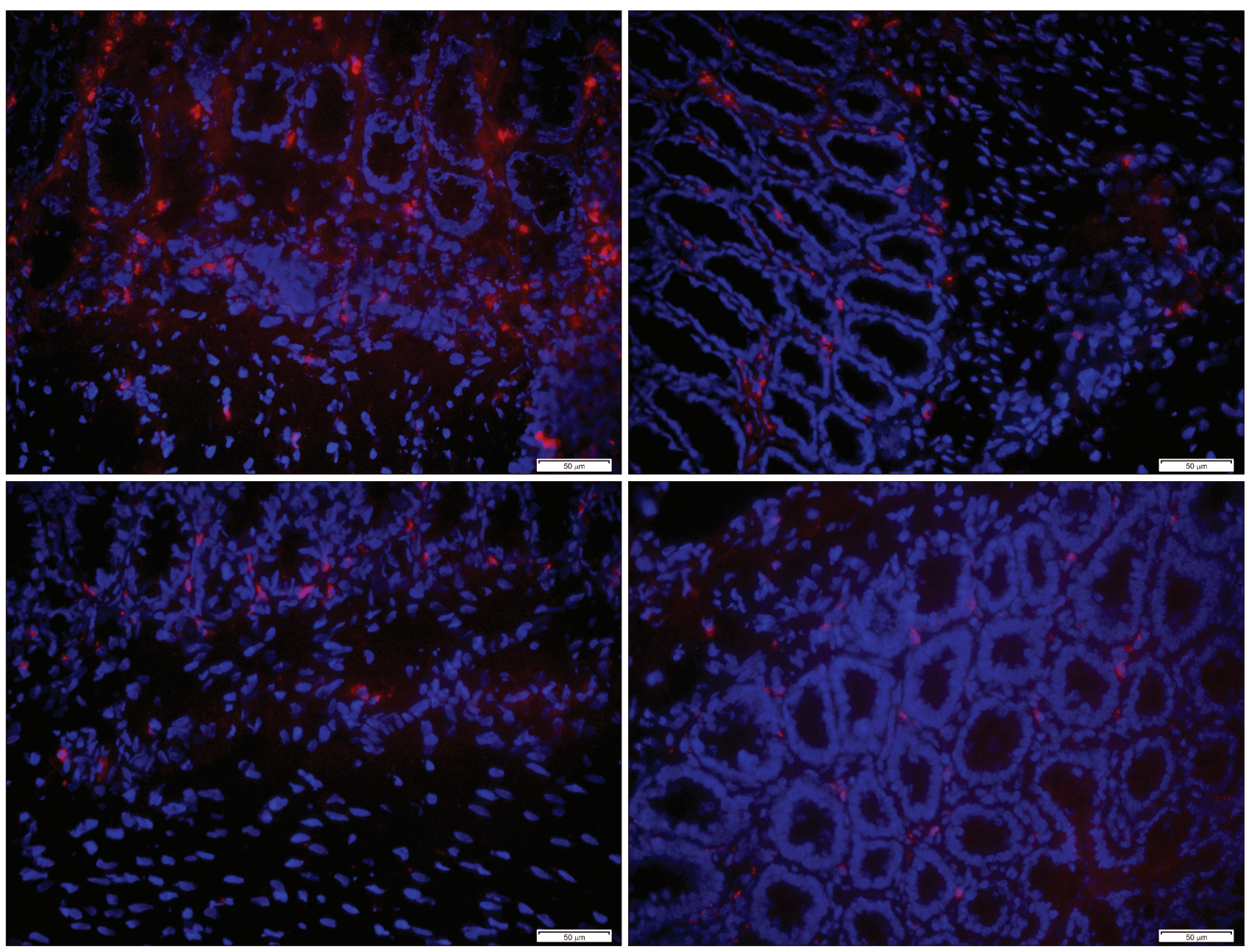

Fig. 2. Colonic immunofluorescence 10 days following TNBS-induced colitis treated by injection of $2 \times 10^{6}$ allogeneic adipose-derived mesenchymal stem cells. The cells have been marked with PKH26 ( $\times 40$ magnification). Upper left image: Rectum; Upper right image: Descending colon; Lower left image: Transverse colon; Lower right image: Right colon. 
Table 1. Thickness measurements of the different components of the rectum (Control vs. Treatment groups)

\begin{tabular}{lccc}
\hline & Control Group $(\mu \mathrm{m})$ & Treated Group $(\mu \mathrm{m}) *$ & $\mathrm{p}$ value \\
\hline Mucosa & $341.81 \pm 56.42$ & $310.27 \pm 51.39$ & 0.131 \\
Submucosa & $361.69 \pm 113.08$ & $340.8 \pm 92.78$ & 0.705 \\
Muscularis propria & $319.25 \pm 74.66$ & $391.27 \pm 85.12$ & 0.96 \\
Full-thickness of bowel & $1022.76 \pm 187.15$ & $1042.34 \pm 111.73$ & 0.762 \\
\hline
\end{tabular}

*Mann-Whitney $U$ test.

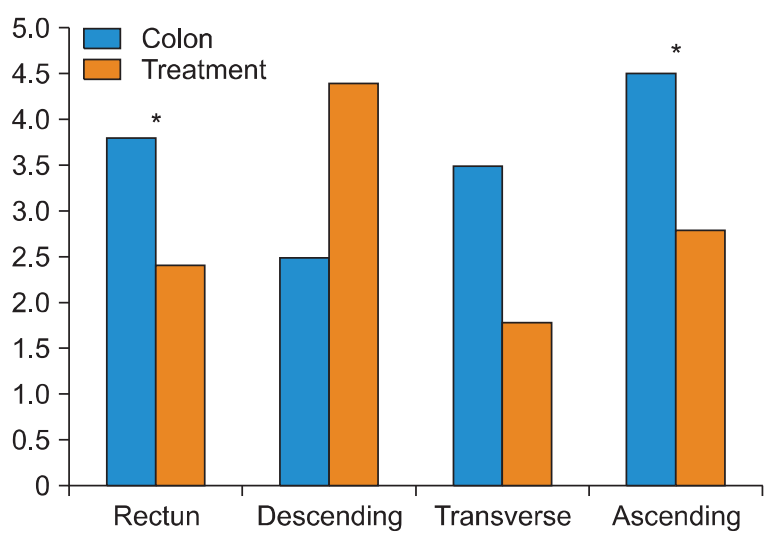

\begin{tabular}{|l|c|c|c|}
\hline & Control & Treatment & $p$ \\
\hline Rectum & $3.80 \pm 2.74$ & $1.50 \pm 2.37$ & $0.017^{*}$ \\
\hline Descending & $1.10 \pm 1.97$ & $0.30 \pm 0.48$ & 0.47 \\
\hline Transverse & $1.70 \pm 2.36$ & $0.70 \pm 2.21$ & 0.19 \\
\hline Ascending & $2.50 \pm 1.08$ & $0.20 \pm 0.42$ & $0.0001^{*}$ \\
\hline
\end{tabular}

Fig. 3. Comparative Hunter scoring of the different parts of the coIon after TNBS-induced colitis (Control vs. ADSC-treated groups).

gut bacteria lying in close proximity to the richest immunological component of the body, where the regulated mucosal barriers of organisms supervise both the host-microbial interchange and mucosal repair. Inflammatory bowel diseases represent a failure of these barrier mechanisms with a deregulated systemic and mucosal immune response directed towards intraluminal antigens; an effect which is enabled by microbial factors and an underlying genetic susceptibility $(23,24)$.

Any of the available animal models of human IBD will be less than ideal and do not replicate fistulous disease or remitting/relapsing variants (25). In 19/20 of our rats rectal TNBS instillation showed a preferential inflammation in the rectum and the right colon most likely consequent upon Trendelenburg positioning of the animals and because of an expected longer contact time between the hapten and the right colonic mucosa $(4,26)$. It is also likely that the distribution of inducible colitis affected the site-specificity of the observed response to allogeneic ADSCs.
Similar to our study, Fawsy et al. showed that allogeneic bone marrow-derived MSCs could induce colon repair with a concomitant significant decrease in the inflammatory response after rectal installation in the rat of 3\% acetic acid (27).

The mesenchymal stromal cell (MSC) is an attractive form of therapy in both experimental and clinical IBD where these characterized cells have a capacity to inhibit the activation of $\mathrm{T}$ lymphocytes and $\mathrm{B}$ and NK cells as well as impair dendritic cell maturation $(28,29)$. These cells are advantageous to use because of their high replicative capacity in vitro and are found in a variety of sites including adipose tissue, synovium, umbilical cord blood and peripheral blood. The MSC is easy to culture with low immunogenicity and high expansion potential permitting ready off-the-shelf treatment with allogeneic cells. The further immunological advantage of the MSC is that it has no antigen-presenting properties and does not express major histocompatibility complex Class II antigen or costimulatory molecules. This ensures that their use does not induce any broad $\mathrm{T}$ cell proliferation and abrogates any allo-reactive $\mathrm{T}$ cell responses (30).

The clinical use of MSCs in IBD has been limited and the reported responses have been conflicting. An early phase II study by Onken et al. (11) of low- $\left(2 \times 10^{6} \mathrm{MSCs}\right)$ and high-dose $\left(8 \times 10^{6} \mathrm{MSCs}\right)$ showed a good level of responsiveness in refractory $\mathrm{CD}$. This ushered in the double-blind clinical trial conducted by the Osiris Therapeutic Group (12) which compared intravenous hematopoietic stem cells with bone marrow-derived MSCs $\left(\operatorname{Proxymal}^{\mathbb{R}}\right.$ ), however, this trial was interrupted because of a higher than expected placebo response. As IBD represents a disorder of immune dysregulation, it was further postulated that high-dose immune ablation with a complete immune system 'reboot' could potentially eliminate the proliferation of detrimental $\mathrm{T}$ cell repertoires. Although this would not impact genetic influences, remission might persist even when environmental triggers remain. This approach has not, unfortunately, proven useful since patients with refractory CD treated with an autologous hematopoietic stem cell transplant not only failed to respond but experi- 


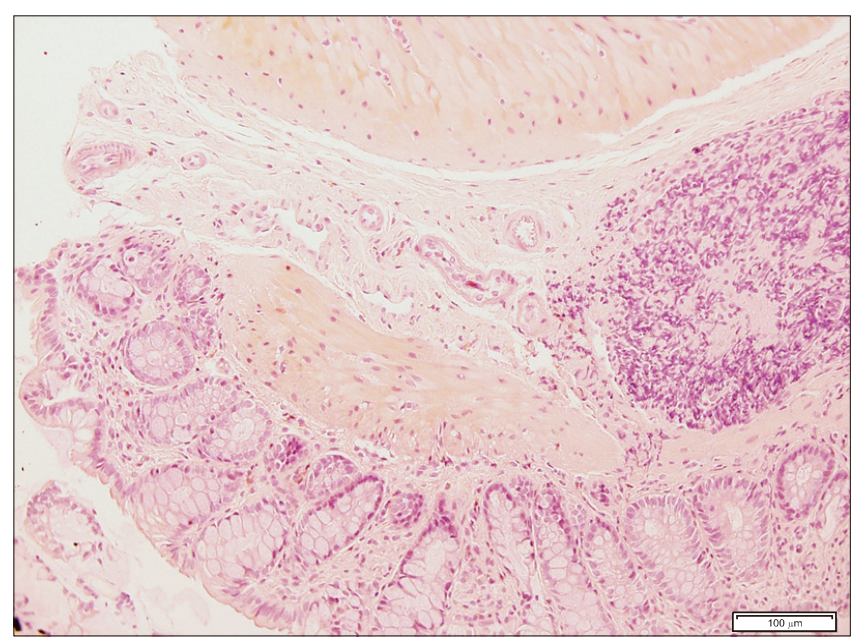

Rectum control

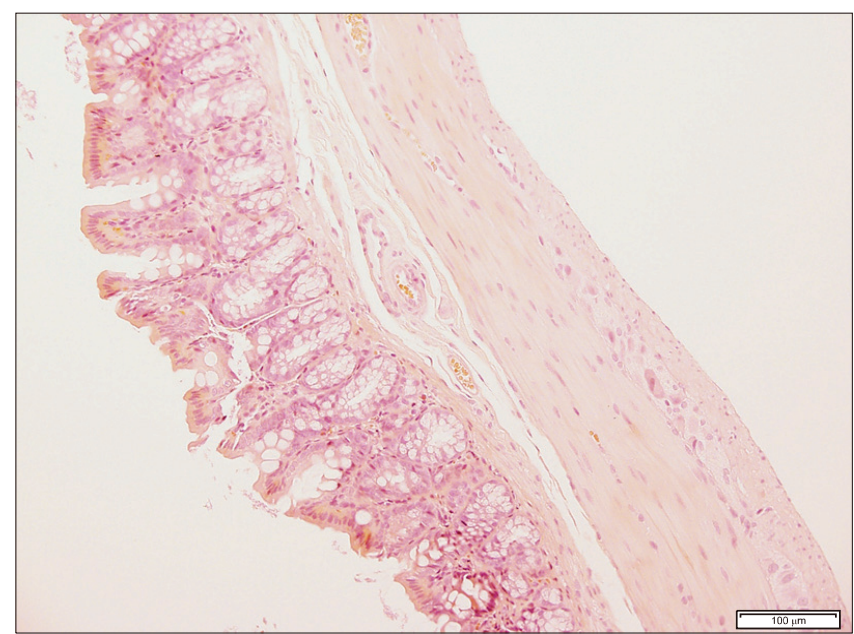

Descending control

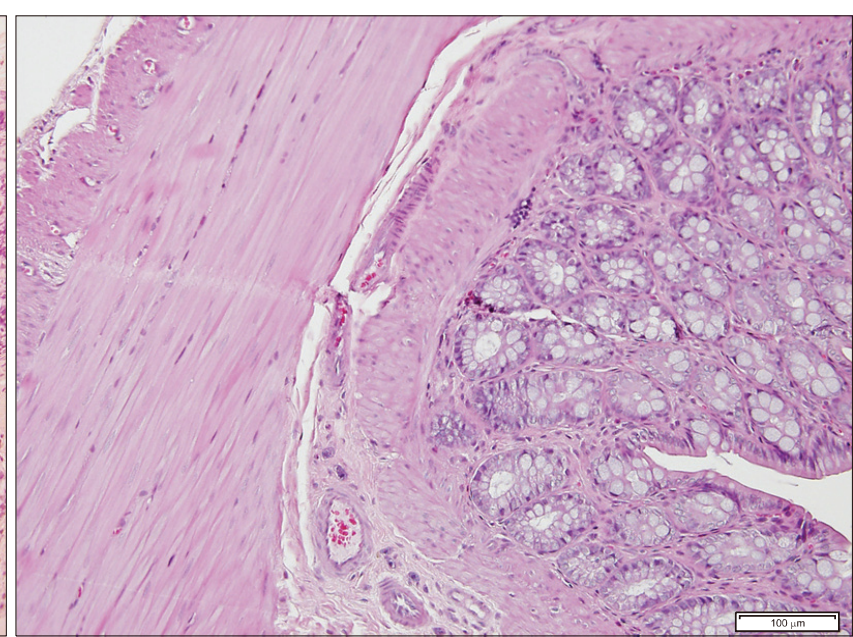

Rectum treatment

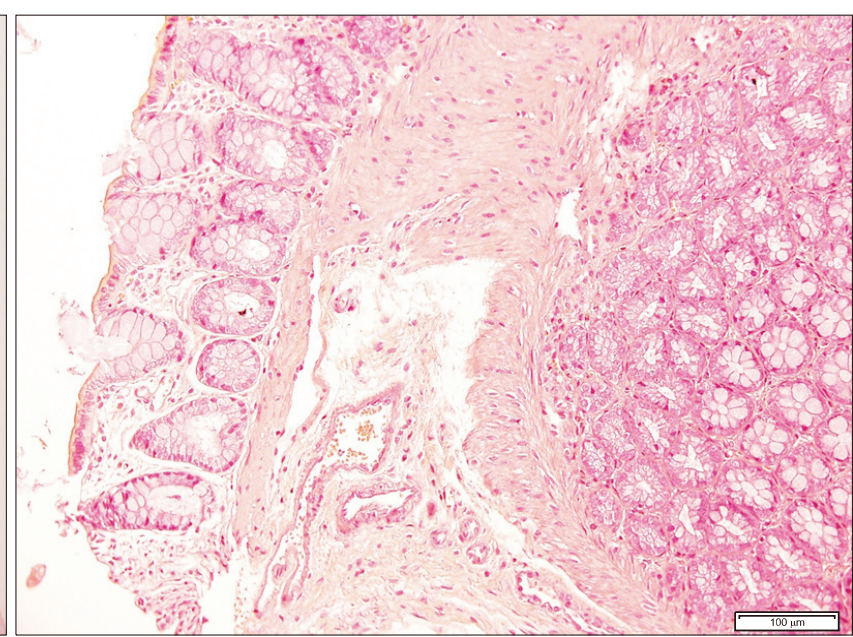

Descending treatment

Fig. 4. Haematoxylin and eosin histology of the different colonic sections (Left: Control group; 1 rectum, 3 Descending colon, 5 Transverse colon, 7 Ascending colon - Right: ADSC-treated group; 2 rectum, 4 Descending colon, 6 Transverse colon, 8 Ascending colon). $\times 20$ magnification.

enced significant toxicity (31).

It is possible that MSC treatment may prove particularly useful in IBD patients resistant to biologic therapies. Given that one-third of all CD patients fail to respond to anti-TNF therapies and that one-third of initial responders show transient loss of response requiring a switch to another biological agent (32), newer modes of biologic therapy are required. In this respect, our group conducted a phase III international clinical trial in perianal CD patients comparing a preparation of allogeneic MSCs with placebo and showing a higher clinical and radiological response rate with MSC treatment after 24 weeks of follow-up (33). Responses were particularly noted in those patients who had initially failed with anti-TNF therapies.

The precise therapeutic mode of action of MSCs is not, however, completely understood with many postulated mechanisms. These include multipotent differentiation, tissue migration, cell-cell contact-dependent surface molecule immunosuppression and the secretion of a range of angiogenic soluble factors (34). As far as we are aware ours is the first such study which shows the homing migration of MSCs to areas of experimentally-induced colitis following rectal installation. In this model, fluorescence-marked cells can be identified clustering in areas of discrete ulceration (most notably around the crypt base and the vasculature of the submucosa), in parts of the colon distant from the treatment site. This migratory effect is similar to the MSC distribution found in other types of inflammation (35). The further idea that these cellular infiltrates diminish upon the remission of lesions suggests that they are 


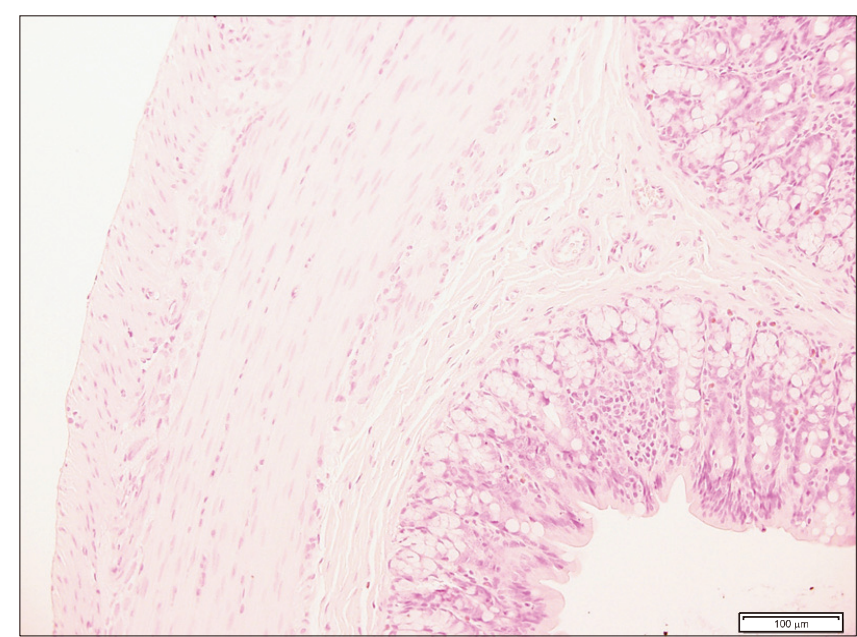

Transverse control

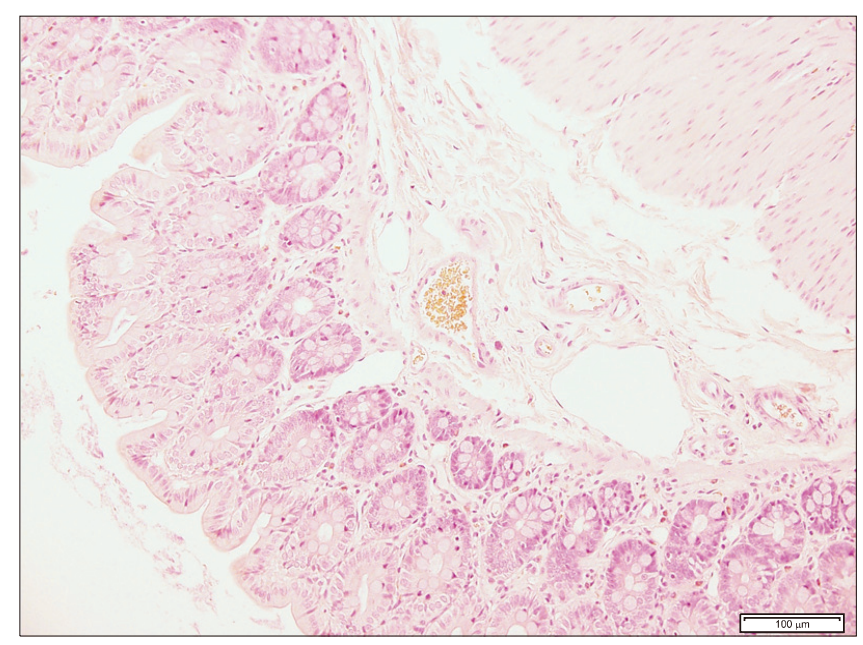

Ascending control

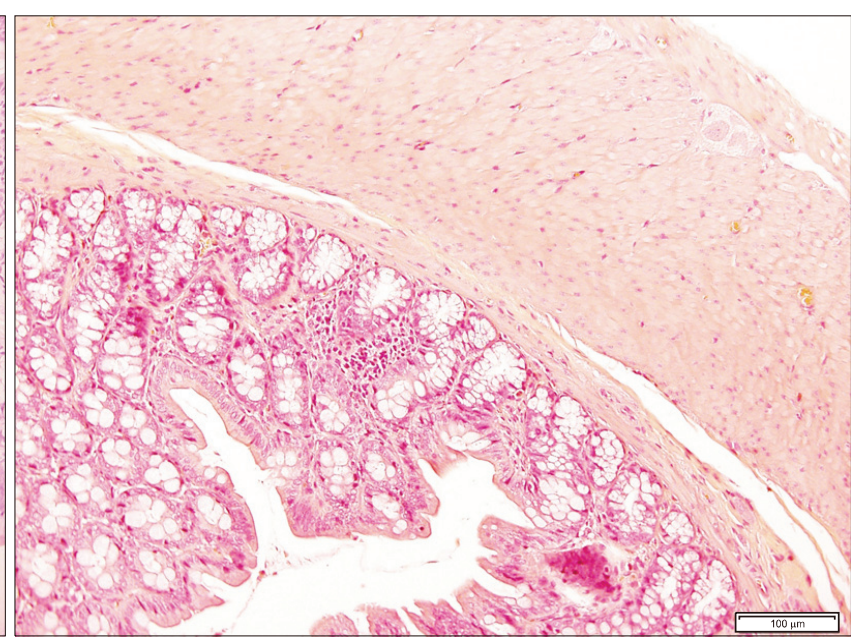

Transverse treatment

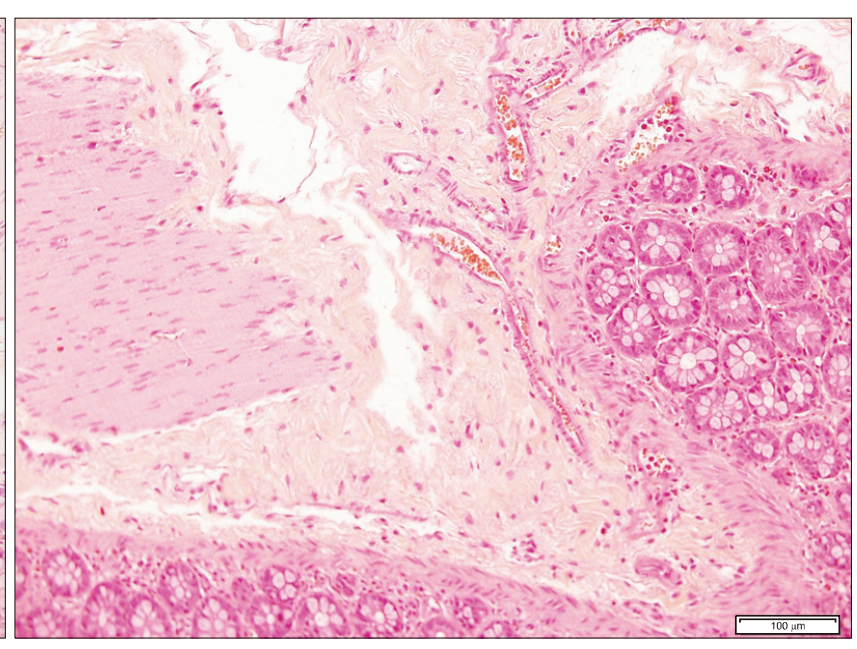

Ascending treatment

Fig. 4. Continued.

also integral in wound/intestinal healing (36).

Recently, it has been published a research regarding the best MSC delivery route for the treatment of experimental colitis. After inducing experimental colitis in rats, the cells were administered via intravenous, intraperitoneal and anal. Route intraperitoneal showed better colitis recovery and might be the optimum MSCs delivery route for the treatment of DSS-induced colitis (37).

Our study is subject to several important limitations. Although the method of experimental colitis is well established, other models may prove more suitable for therapeutic study and the action of administered MSCs will be more complicated than the mere migration of potentially immunocompetent cells. Ancillary mechanisms of action apart from the stimulation of innate immunoresponsiveness, will include the specific blockade of proinflammatory cytokines, the abrogation of inflammatory cell recruitment and the inhibition of $\mathrm{T}$ cell proliferation with the induction of $\mathrm{T}$ cell apoptosis (38). It is appreciated that comparisons of semiquantitative histopathological scores of inflammation in animal colonic tissue are not strictly comparable with the instruments of response typically used in clinical studies, such as the CDAI. In this respect, the data from preclinical work has only so far shown a limited capacity to predict efficacy in clinical trials (4). The derivation of MSCs (adipose- vs. bone-marrow and allogeneic $v s$. autologous) is considered important in this regard, as is their method of delivery (local vs. intravenous). Differences in cell source and administrative protocol may account for some of the conflicting data concerning luminal IBD following systemic autologous MSC administration (39).

Further differences in MSC responsiveness may result (potentially as in our study) from the use of cryopreserved 
MSCs. Here, the freeze-thawing process has been reported to attenuate MSC biodistribution and immunosuppressive properties when compared with actively growing in vitro MSC cultures (40). In this context prolonged cellular expansion may lead to a senescent immunophenotype. The lessons learned concerning MSC responsiveness in animal experiments are difficult to translate to humans where the utilization of allogeneic MSCs derived from random MHC-unmatched donors and autologous MSCs studies are not strictly comparable. There are also important species differences in the mechanisms of MSC immunosuppression, where human MSCs convert tryptophan into the immunosuppressive catabolite Kynurenine through indoleamine 2,3 dioxygenase but where murine MSCs use the inducible L-Arginine nitric oxide synthase pathway (41). In summary, our study shows that local colonic injection of allogeneic adipose-derived MSCs is feasible and safe. This has resulted in a homing of cells to areas of chemically-induced colitis in the rat, including to regions of the colon distant from the MSC treatment site. In this IBD model, the dose and timing of therapeutic MSCs remains to be determined but this approach with further experimentation potentially offers a simple and readily reproducible treatment option for future use in clinical practice.

\section{Acknowledgements}

A Grant for this experimental work was provided by Nodo-Biobanco Hospital Virgen de Rocio-IBiS (Biobanco SSPA y Red Biobancos-ISCIII-PT13/0010/0056).

The authors also thank Andrew Zbar and Mariano García-Herranz for the critical review of the manuscript.

\section{Potential Conflict of Interest}

The authors have no conflicting financial interest.

\section{References}

1. Kaplan GG. The global burden of IBD: from 2015 to 2025. Nat Rev Gastroenterol Hepatol 2015;12:720-727

2. Kellermayer R. Challenges for epigenetic research in inflammatory bowel diseases. Epigenomics 2017;9:527-538

3. Ogura Y, Bonen DK, Inohara N, Nicolae DL, Chen FF, Ramos R, Britton H, Moran T, Karaliuskas R, Duerr RH, Achkar JP, Brant SR, Bayless TM, Kirschner BS, Hanauer SB, Nuñez G, Cho JH. A frameshift mutation in NOD2 associated with susceptibility to Crohn's disease. Nature 2001;411:603-606

4. Valatas V, Bamias G, Kolios G. Experimental colitis models: Insights into the pathogenesis of inflammatory bowel disease and translational issues. Eur J Pharmacol 2015;759: 253-264
5. Cominelli F, Arseneau KO, Rodriguez-Palacios A, Pizarro TT. Uncovering pathogenic mechanisms of inflammatory bowel disease using mouse models of Crohn's disease-like ileitis: what is the right model? Cell Mol Gastroenterol Hepatol 2017;4:19-32

6. Stagg J, Galipeau J. Mechanisms of immune modulation by mesenchymal stromal cells and clinical translation. Curr Mol Med 2013;13:856-867

7. Hoogduijn MJ, Betjes MG, Baan CC. Mesenchymal stromal cells for organ transplantation: different sources and unique characteristics? Curr Opin Organ Transplant 2014; 19:41-46

8. Dominici M, Le Blanc K, Mueller I, Slaper-Cortenbach I, Marini F, Krause D, Deans R, Keating A, Prockop Dj, Horwitz E. Minimal criteria for defining multipotent mesenchymal stromal cells. The International Society for Cellular Therapy position statement. Cytotherapy 2006;8: 315-317

9. Krampera M, Galipeau J, Shi Y, Tarte K, Sensebe L; MSC Committee of the International Society for Cellular Therapy (ISCT). Immunological characterization of multipotent mesenchymal stromal cells--The International Society for Cellular Therapy (ISCT) working proposal. Cytotherapy 2013;15:1054-1061

10. Kashyap A, Forman SJ. Autologous bone marrow transplantation for non-Hodgkin's lymphoma resulting in longterm remission of coincidental Crohn's disease. Br J Haematol 1998;103:651-652

11. Onken J, Gallup D, Hanson J, Pandak M, Custer L. Successful outpatient treatment of refractory Crohn's disease using adult mesenchymal stem cells (Abstract). American College of Gastroenterology Conference Annual Meeting Las Vegas October 2006. Available from: http:// universe.gi.org/contentitem.asp?c $=1047$.

12. Hawkey CJ, Hommes DW. Is stem cell therapy ready for prime time in treatment of inflammatory bowel diseases? Gastroenterology 2017;152:389-397.e2

13. de la Portilla F, Alba F, García-Olmo D, Herrerías JM, González FX, Galindo A. Expanded allogeneic adipose- derived stem cells (eASCs) for the treatment of complex perianal fistula in Crohn's disease: results from a multicenter phase I/IIa clinical trial. Int J Colorectal Dis 2013;28: 313-323

14. Morris GP, Beck PL, Herridge MS, Depew WT, Szewczuk MR, Wallace JL. Hapten-induced model of chronic inflammation and ulceration in the rat colon. Gastroenterology 1989;96:795-803

15. Pfeiffer CJ, Sato S, Qiu BS, Keith JC, Evangelista S. Cellular pathology of experimental colitis induced by trinitrobenzenesulphonic acid (TNBS): protective effects of recombinant human interleukin-11. Inflammopharmacology 1997;5:363-381

16. Millar AD, Rampton DS, Chander CL, Claxson AW, Blades S, Coumbe A, Panetta J, Morris CJ, Blake DR. Evaluating the antioxidant potential of new treatments for inflammatory bowel disease using a rat model of colitis. 
Gut 1996;39:407-415

17. Bourin P, Bunnell BA, Casteilla L, Dominici M, Katz AJ, March KL, Redl H, Rubin JP, Yoshimura K, Gimble JM. Stromal cells from the adipose tissue-derived stromal vascular fraction and culture expanded adipose tissue-derived stromal/stem cells: a joint statement of the International Federation for Adipose Therapeutics and Science (IFATS) and the International Society for Cellular Therapy (ISCT). Cytotherapy 2013;15:641-648

18. Boquest AC, Shahdadfar A, Brinchmann JE, Collas P. Isolation of stromal stem cells from human adipose tissue. Methods Mol Biol 2006;325:35-46

19. Yoshimura K, Shigeura T, Matsumoto D, Sato T, Takaki Y, Aiba-Kojima E, Sato K, Inoue K, Nagase T, Koshima I, Gonda K. Characterization of freshly isolated and cultured cells derived from the fatty and fluid portions of liposuction aspirates. J Cell Physiol 2006;208:64-76

20. Zhu Y, Liu T, Song K, Fan X, Ma X, Cui Z. Adipose-derived stem cell: a better stem cell than BMSC. Cell Biochem Funct 2008;26:664-675

21. Poon RY, Ohlsson-Wilhelm BM, Bagwell CB, Muirhead KA. Use of PKH membrane intercalating dyes to monitor cell trafficking and function. In: Diamond RA, DeMaggio $S$, editors. In Living Color: Protocols in Flow Cytometry and Cell Sorting. New York, NY: Springer-Verlag; 2000. 302-352

22. Hunter MM, Wang A, Hirota CL, McKay DM. Neutralizing anti-IL-10 antibody blocks the protective effect of tapeworm infection in a murine model of chemically induced colitis. J Immunol 2005;174:7368-7375

23. Chassaing B, Darfeuille-Michaud A. The commensal microbiota and enteropathogens in the pathogenesis of inflammatory bowel diseases. Gastroenterology 2011;140: $1720-1728$

24. Grégoire C, Lechanteur C, Briquet A, Baudoux É, Baron F, Louis E, Beguin Y. Review article: mesenchymal stromal cell therapy for inflammatory bowel diseases. Aliment Pharmacol Ther 2017;45:205-221

25. Randhawa PK, Singh K, Singh N, Jaggi AS. A review on chemical-induced inflammatory bowel disease models in rodents. Korean J Physiol Pharmacol 2014;18:279-288

26. Motavallian-Naeini A, Andalib S, Rabbani M, Mahzouni P, Afsharipour M, Minaiyan M. Validation and optimization of experimental colitis induction in rats using 2, 4, 6-trinitrobenzene sulfonic acid. Res Pharm Sci 2012;7:159-169

27. Fawzy SA, El-Din Abo-Elnou RK, Abd-El-Maksoud El-Deeb DF, Yousry Abd-Elkader MM. The possible role of mesenchymal stem cells therapy in the repair of experimentally induced colitis in male albino rats. Int J Stem Cells 2013;6:92-103

28. Zuk PA, Zhu M, Mizuno H, Huang J, Futrell JW, Katz AJ, Benhaim P, Lorenz HP, Hedrick MH. Multilineage cells from human adipose tissue: implications for cell-based therapies. Tissue Eng 2001;7:211-228

29. García-Gómez I, Elvira G, Zapata AG, Lamana ML, Ramírez M, Castro JG, Arranz MG, Vicente A, Bueren J,
García-Olmo D. Mesenchymal stem cells: biological properties and clinical applications. Expert Opin Biol Ther 2010;10:1453-1468

30. Krampera M, Glennie S, Dyson J, Scott D, Laylor R, Simpson E, Dazzi F. Bone marrow mesenchymal stem cells inhibit the response of naive and memory antigen-specific T cells to their cognate peptide. Blood 2003;101:3722-3729

31. Hawkey CJ, Allez M, Clark MM, Labopin M, Lindsay JO, Ricart E, Rogler G, Rovira M, Satsangi J, Danese S, Russell N, Gribben J, Johnson P, Larghero J, Thieblemont C, Ardizzone S, Dierickx D, Ibatici A, Littlewood T, Onida F, Schanz U, Vermeire S, Colombel JF, Jouet JP, Clark E, Saccardi R, Tyndall A, Travis S, Farge D. Autologous hematopoetic stem cell transplantation for refractory crohn disease: a randomized clinical trial. JAMA 2015;314:2524-2534

32. Yanai H, Hanauer SB. Assessing response and loss of response to biological therapies in IBD. Am J Gastroenterol 2011;106:685-698

33. Panés J, García-Olmo D, Van Assche G, Colombel JF, Reinisch W, Baumgart DC, Dignass A, Nachury M, Ferrante M, Kazemi-Shirazi L, Grimaud JC, de la Portilla F, Goldin E, Richard MP, Leselbaum A, Danese S; ADMIRE CD Study Group Collaborators. Expanded allogeneic adipose-derived mesenchymal stem cells (Cx601) for complex perianal fistulas in Crohn's disease: a phase 3 randomised, double-blind controlled trial. Lancet 2016;388:1281-1290

34. Mao F, Tu Q, Wang L, Chu F, Li X, Li HS, Xu W. Mesenchymal stem cells and their therapeutic applications in inflammatory bowel disease. Oncotarget 2017;8:38008-38021

35. Karp JM, Leng Teo GS. Mesenchymal stem cell homing: the devil is in the details. Cell Stem Cell 2009;4:206-216

36. Wu Y, Chen L, Scott PG, Tredget EE. Mesenchymal stem cells enhance wound healing through differentiation and angiogenesis. Stem Cells 2007;25:2648-2659

37. Wang M, Liang C, Hu H, Zhou L, Xu B, Wang X, Han Y, Nie Y, Jia S, Liang J, Wu K. Intraperitoneal injection (IP), Intravenous injection (IV) or anal injection (AI)? Best way for mesenchymal stem cells transplantation for colitis. Sci Rep 2016;6:30696

38. Schoeb TR, Bullard DC. Microbial and histopathologic considerations in the use of mouse models of inflammatory bowel diseases. Inflamm Bowel Dis 2012;18:1558-1565

39. Kim N, Cho SG. New strategies for overcoming limitations of mesenchymal stem cell-based immune modulation. Int J Stem Cells 2015;8:54-68

40. Moll G, Alm JJ, Davies LC, von Bahr L, Heldring N, Stenbeck-Funke L, Hamad OA, Hinsch R, Ignatowicz L, Locke M, Lönnies H, Lambris JD, Teramura Y, Nilsson-Ekdahl K, Nilsson B, Le Blanc K. Do cryopreserved mesenchymal stromal cells display impaired immunomodulatory and therapeutic properties? Stem Cells 2014;32:2430-2442

41. Romieu-Mourez R, Coutu DL, Galipeau J. The immune plasticity of mesenchymal stromal cells from mice and men: concordances and discrepancies. Front Biosci (Elite Ed) $2012 ; 4: 824-837$ 